\title{
Influence of crown design and material on chipping-resistance of all-ceramic molar crowns: An in vitro study
}

\section{Wpływ kształtu i materiału pełnoceramicznych koron trzonowców na odporność na odpryskiwanie - badanie in vitro}

\author{
Majed Alsarani 1,2,A-D, Grace De Souza ${ }^{3, A, C, E}$, Amin Rizkalla ${ }^{4, A, C, E}, 0$ mar El-Mowafy, 3, A,C,E-F \\ ${ }^{1}$ Faculty of Dentistry, University of Toronto, Canada \\ ${ }^{2}$ Faculty of Applied Medical Sciences, King Saud University, Riyadh, Saudi Arabia \\ ${ }^{3}$ Department of Restorative Dentistry, Faculty of Dentistry, University of Toronto, Canada \\ ${ }^{4}$ Faculty of Dentistry, Schulich School of Medicine \& Dentistry, University of Western Ontario, London, Canada \\ A - research concept and design; $\mathrm{B}$ - collection and/or assembly of data; $\mathrm{C}$ - data analysis and interpretation; \\ $D$ - writing the article; $E$ - critical revision of the article; $F$ - final approval of the article
}

Address for correspondence

Majed Alsarani

E-mail:majed.alsarani@dentistry.utoronto.ca

Funding sources

This research was supported in part by King Saud University Riyadh, Saudi Arabia.

Conflict of interest

None declared

Received on January 19, 2018

Reviewed on January 21,2018

Accepted on February 2, 2018

DOI

$10.17219 / \mathrm{dmp} / 85000$

Copyright

○ 2018 by Wroclaw Medical University

and Polish Dental Society

This is an article distributed under the terms of the

Creative Commons Attribution Non-Commercial License

(http://creativecommons.org/licenses/by-nc-nd/4.0/)

\begin{abstract}
Background. All-ceramic restorations have become popular and the trend is ongoing. However, the incidence of chipping within the veneering layer has been a commonly reported failure in clinical practice.

Objectives. The aim of this in vitro study was to evaluate the effect of ceramic crown design (monolithic vs bi-layered) and material on the chipping resistance of molar crowns submitted to compressive cyclic loading.

Material and methods. Fifty identical epoxy resin replicas of a mandibular 15t $^{\text {st }}$ olar with crown preparation were divided into 5 groups $(n=10)$ as follows: the MLD group - monolithic CAD/CAM lithium-disilicate glass-ceramic (LDGC) crowns; 30 zirconia cores were veneered with either feldspathic porcelain by hand-layering technique (ZHL) or by heat-pressing technique (ZVP), or with milled LDGC veneers and subsequently fused to the cores (ZLD); 10 porcelain-fused-to-metal (PFM) crowns acted as a control group. All crowns were cemented using Panavia ${ }^{\oplus}$ F2.0 resin cement (Kuraray Dental, Tokyo, Japan). After storage in water at $37^{\circ} \mathrm{C}$ for 1 week, the specimens were subjected to compressive cyclic loading at the mesiobuccal cusp which was tilted at $30^{\circ}$. A load cycle of $50-450 \mathrm{~N}$ was used and specimens were maintained in an aqueous environment throughout 500,000 cycles in a universal testing machine (Instron, Norwood, USA). The data was statistically analyzed at 5\% significant level with Fisher's exact test and Kaplan-Meier survival analysis.
\end{abstract}

Results. Significant differences in survival rates of the specimens used in the groups $(p<0.001)$ were found. Specimens of the PFM, ZHL and ZVP groups underwent failures at different stages of the 500,000 fatigue cycles, while specimens of the MLD and ZLD groups survived the entire fatigue test. ZHL and ZVP crowns had the worst chipping-resistance, while PFM crowns performed slightly better. The Kaplan-Meier test revealed significantly higher survival rates for the MLD and ZLD specimens compared to the other 3 groups.

Conclusions. The use of LDGC as a monolithic molar crown and as a veneer over a zirconia core resulted in superior resistance to cuspal chipping.

Key words: fatigue, crown, chipping, monolithic, posterior

Słowa kluczowe: badanie zmęzzeniowe, korona, odpryski, monolityczny, tylny 


\section{Introduction}

Computer-aided design/computer-aided manufacturing (CAD/CAM) technology enables precise milling of crowns and fixed dental prostheses (FDP) from a variety of ceramic-based blocks including high-strength materials such as lithium-disilicate glass-ceramic (LDGC) and zirconia. ${ }^{1}$ Because of the ongoing trend toward more esthetically-pleasing and biologically-compatible restorations, different all-ceramic systems have been developed. ${ }^{2}$ The use of yttrium partially-stabilized zirconia polycrystal (Y-TZP) has gained popularity due to the superior mechanical properties of the material such as high flexural strength (>900 $\mathrm{MPa}$ ) and compressive strength $(2000 \mathrm{MPa}){ }^{3}$ This material is capable of providing a strong framework for dental restorations which have a reportedly low failure rate. ${ }^{4,5}$

Originally, the application of high-crystalline zirconia in dental restoration was limited to substructures due to its high opacity. Veneering is typically applied over zirconia cores to provide a more natural appearance. ${ }^{6}$ In such a complex, the veneering porcelain is the weaker component, and a high incidence of occlusal chipping of posterior bi-layered crowns has been reported. ${ }^{7,8}$ The failure rate observed for both tooth-supported and implant-supported bi-layered zirconia crowns has varied between $3 \%$ and $50 \%{ }^{9,10}$ Traditionally, veneering porcelain is hand-layered over the zirconia core, however a pressed-on veneering technique is an alternative. It has been reported that the pressed-on veneering technique minimizes chipping in zirconia crowns compared to the conventional (handlayering) technique. ${ }^{11,12}$

There are different hypotheses for the high chipping rates of all-ceramic restorations, including the mismatch of coefficient of thermal expansion (CTE) between the core and the veneer material, uneven thickness of the porcelain veneer, and the quality of the bonded interface between the veneer and the core material. ${ }^{13}$ Significant CTE mismatch would potentially create stresses at the core/veneer interface, which might cause the porcelain veneer chipping. To enhance the overall strength of the core/veneer complex, the veneering porcelain should ideally have lower CTE compared to that of the core in order to create compressive stresses during cooling of the restoration. ${ }^{14}$ In addition to variability in CTE, the thicknesses of the veneering porcelain and the underlying core also have an impact on the chipping behavior of the veneering porcelain. To that end, studies have suggested that applying a minimum veneer thickness to enhance the adequate esthetic and functional needs would increase the strength of bi-layered restorations. ${ }^{6,15}$ Furthermore, inadequate bond strength between the veneering porcelain and the zirconia core could be the major underlying factor that causes chipping. ${ }^{16}$ Reportedly, factors that lead to inadequate bond strength between the zirconia core and the veneering porcelain include flaws in the veneering porcelain created during layering, liner material application and variability in zirconia surface preparation. ${ }^{17}$

As an alternative to zirconia cores veneered with porcelain, monolithic (full-contoured) crowns made of LDGC may be employed due to their relatively high flexural strength $(360 \mathrm{MPa})$ and better translucency compared to high crystalline zirconia. This seems to be a reliable alternative to bi-layered zirconia-based crowns. ${ }^{2,18}$ The short-term clinical performance of monolithic crowns after 24-month observation was reported to be promising, with a survival rate of $98-100 \% \cdot{ }^{19,20}$ An in vitro study demonstrated that bulk fracture occurred at higher load levels for the monolithic LDGC crowns compared to ones made of hand-layered veneers over zirconia cores due to better stress distribution. ${ }^{21}$ Alternatively, CAD/ CAM milled LDGC veneers applied over zirconia cores increased the mechanical stability of the restoration and seemed to be a promising alternative to minimize chipping and fracture. ${ }^{18}$

The purpose of this study was to evaluate the effects of crown design (monolithic vs bi-layered), material and layering technique on the chipping resistance of all-ceramic molar crowns. The null hypothesis was that there is no effect of crown design, material or layering technique on the chipping resistance of all-ceramic crowns.

\section{Material and methods}

A ceramic crown preparation was made on an epoxyresin mandibular $1^{\text {st }}$ molar with axial wall reduction resulting in a $1 \mathrm{~mm}$ shoulder finishline. It was located $1 \mathrm{~mm}$ above the cementoenamel junction. Occlusal surface reduction was at least $1.5 \mathrm{~mm}$. Line angles between occlusal and axial surfaces were prepared rounded. The prepared tooth was used to fabricate 50 replicas using a highly filled epoxy-resin (Viade Products Inc., Camarillo, USA). The replicas were placed in a dentiform with adjacent teeth on both proximal sides to simulate a clinical situation of a molar needing crown. The materials used for crown fabrication and cementation are listed in Table 1.

Tooth replicas were divided into 5 crown groups $(n=10)$ as follows: MLD - monolithic LDGC crowns; ZHL - zirconia copings veneered by hand-layering technique; ZVP - zirconia copings veneered by heat-pressing technique; ZLD - zirconia copings veneered with milled LDGC; PFM - porcelain-fused-to-metal crowns (control group).

For the MLD group, the prepared tooth, adjacent and opposing teeth were coated with a thin layer of optical reflective powder (IPS Contrast Spray, Ivoclar Vivadent, Schaan, Liechtenstein) and a CEREC 3D intra-oral scanner (Sirona Dental Systems, Bensheim, Germany) was utilized to capture optical images. A full-contour crown was virtually-designed (CEREC 3.84, Sirona) and milled out of an IPS e.max CAD block using a CEREC milling 
Table 1. Material properties (according to the manufacturer's instructions data)

\begin{tabular}{|c|c|c|c|c|}
\hline Material and lot & Compositions & Fabricating technique & Flexural strength (MPa) & CTE $\left(\times 10^{-6}\right)$ \\
\hline IPS e.max Ceram (S00837) & nano-fluorapatite glass-ceramic & manual application & 90 & 9.5 \\
\hline IPS e.max ZirPress (P76153) & fluorapatite glass-ceramic & pressing technique & 110 & 9.8 \\
\hline IPS e.max CAD (R67755) & lithium-disilicate glass-ceramic & CAD/CAM & 360 & $10.2-10.5$ \\
\hline IPS e.max ZirCAD (R71099) & yttrium stabilized zirconium oxide & CAD/CAM & 900 & 10.8 \\
\hline Argely NP Supreme (35052 03/10) & Co: 61\%, Cr: 27\%, Mo: 6\%,W: 5\% & laser sintering technique & 475 & 14.1 \\
\hline IPS d.Sign (R73590) & leucite glass-ceramic & manual application & $80 \pm 25$ & 12.6 \\
\hline IPS e.max CAD crystal/connect (R66132) & fusion glass-ceramic & manual application & 160 & 9.5 \\
\hline
\end{tabular}

CTE - coefficient thermal expansion; CAD/CAM - computer-aided design and computer-aided manufacturing.

unit (Sirona). The milled crowns were then subjected to a crystallization firing cycle in a Programat furnace (Ivoclar Vivadent). Glazing paste was applied to the outer surfaces of the crowns before placement in the furnace.

For the ZHL, ZVP and ZLD groups, replicas were digitally-scanned as described above and copings were virtually-designed. Copings of a uniform thickness of $0.5 \mathrm{~mm}$ were then milled from Y-TZP blocks (IPS e.max ZirCAD, Ivoclar Vivadent) using CEREC inLab 3.84 (Sirona). The milled copings were then subjected to final sintering in a furnace following the manufacturer's instructions. The sintered copings were then assigned to 3 groups according to the porcelain veneering technique. Ten zirconia copings were veneered with manually-added porcelain (IPS e.max Ceram, Ivoclar Vivodent) (ZHL), while another 10 copings were veneered with heat-pressed porcelain (IPS e.max ZirPress, Ivoclar Vivadent) (ZVP). IPS e.max ZirLiner was applied to establish a bonding between the veneer materials and the zirconia copings. For the remaining 10 zirconia copings, CAD/CAM-milled LDGC veneers (IPS e.max CAD) were fused to the zirconia copings using a glass fusion bonder (IPS e.max CAD crystall/connect) (ZLD).

For the PFM crowns, copings were virtually-designed (CEREC 3D 3.84, Sirona) with a $0.5 \mathrm{~mm}$ uniform thickness. They were then fabricated with laser-sintering technology using a non-precious metal alloy (Argely NP Supreme, IdentAlloy, Glastonbury, USA). The metal copings were manually-veneered (IPS d.Sign, Ivoclar Vivadent). One experienced dental technician fabricated all PFM crowns.

All crowns were tried-in onto their corresponding tooth replicas in order to confirm proper seating and adequate marginal fit. The crowns were then cemented to their replicas with dual-cured resin cement (Panavia F2.0, Kuraray Dental, Tokyo, Japan). For all metal and zirconia copings, the intaglio surfaces were grit-etched with $50 \mu \mathrm{m}$ aluminum oxide powder under 1 bar pressure for $5 \mathrm{~s}{ }^{22}$ For the LDGC crowns, the intaglio surfaces were etched for $20 \mathrm{~s}$ with hydrofluoric acid (IPS Ceramic Etching Gel, Ivoclar Vivadent). The crowns were cleaned with distilled water in an ultrasonic bath. The surfaces were then coated with a layer of silane-coupling agent (Mono-Bond Plus, Ivoclar Vivadent). Each crown was seated onto its corresponding replica, excess cement was removed and Oxyguard II (Ku- raray) was applied to cover the margins for $3 \mathrm{~min}$. A $10 \mathrm{~N}$ load was applied onto the occlusal surface for $15 \mathrm{~min}$. Light-curing was performed for $20 \mathrm{~s}$ on each of the crown surfaces. Overall length of a specimen (tooth + crown) was measured before and after cementation with a digital caliper to ensure complete seating of the crowns. The specimens were then stored in distilled water at $37^{\circ} \mathrm{C}$ for 1 week prior to the compressive cyclic loading test.

Cyclic loading was applied to each specimen in a universal testing machine (Instron 8501, Instron, Norwood, USA). The specimens were embedded in a special acrylic holder to ensure that loading was applied to the mesiobuccal (MB) cusp incline set at $30^{\circ}$. A testing chamber was filled with distilled water with the specimen secured at its center. Cyclic loading was applied using a cone shaped indenter applied at the center of the MB incline (Fig. 1). Each specimen was subjected to compressive cyclic load-

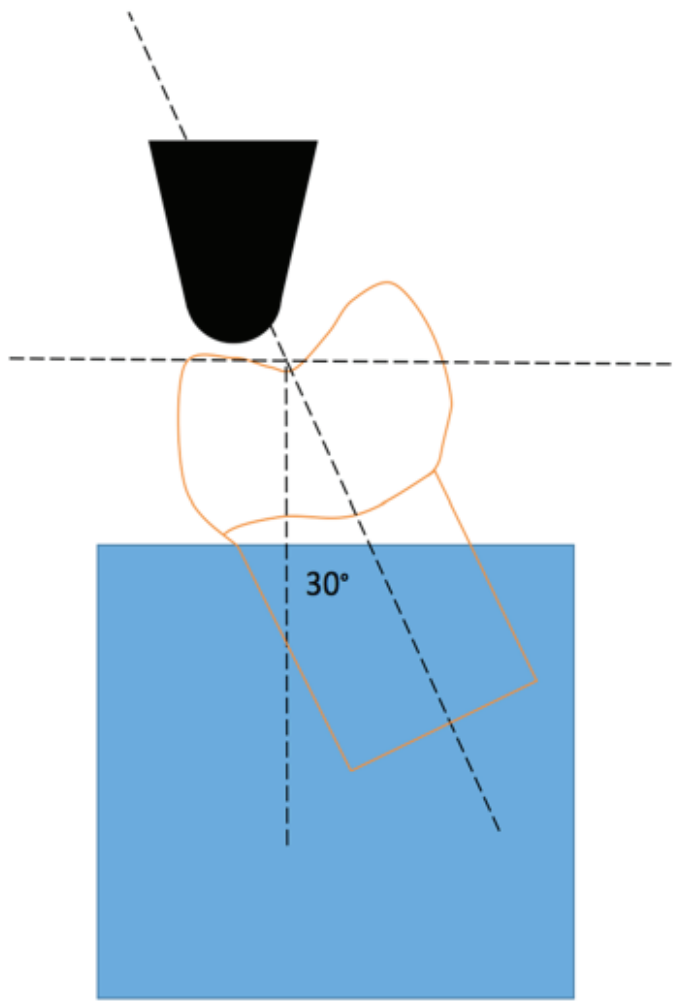

Fig. 1. Schematic illustration of load application at the incline of the mesiobuccal cusp 
Table 2. Number of cycles at which each specimen failed. The lowest and highest numbers of cycles at which failure occurred are marked in bold. Specimens that reached 500,000 cycles did not fracture

\begin{tabular}{|c|c|c|c|c|c|}
\hline Sample & $\mathrm{ZHL}$ & MLD & ZVP & ZLD & PFM \\
\hline 1 & 8,513 & 500,000 & 2,291 & 500,000 & 40,957 \\
\hline 2 & 29,240 & 500,000 & 19,347 & 500,000 & 98,984 \\
\hline 3 & 1,120 & 500,000 & 9,852 & 500,000 & 49,279 \\
\hline 4 & 3,514 & 500,000 & 41,191 & 500,000 & 320,712 \\
\hline 5 & 1,692 & 500,000 & 2,133 & 500,000 & 1,458 \\
\hline 6 & 24,009 & 500,000 & 31,467 & 500,000 & 8,504 \\
\hline 7 & 13,924 & 500,000 & 47,169 & 500,000 & 17,096 \\
\hline 8 & 4,484 & 500,000 & 1,282 & 500,000 & 4531 \\
\hline 9 & 10,329 & 500,000 & 3,203 & 500,000 & 9,106 \\
\hline 10 & 5,206 & 500,000 & 23,520 & 500,000 & 236,896 \\
\hline
\end{tabular}

ZHL - zirconia copings veneered by hand-layering technique; MLD - monolithic LDGC crowns; ZVP - zirconia copings veneered by heat-pressing technique; ZLD - zirconia coping veneered with milled LDGC; PFM - porcelain-fused-to-metal crowns; LDGC - lithium-disilicate glass-ceramic.

ing at $20 \mathrm{~Hz}$ for 500,000 cycles. Each cycle started at $50 \mathrm{~N}$ and completed at $450 \mathrm{~N}$. Where possible, the machine was stopped after 250,000 cycles and the specimens were examined under light microscope to check for the presence of cracks. If no defects were detected, 250,000 additional cycles were applied and the specimens were then microscopically re-inspected. When chipping or fracture of the specimen occurred before the completion of the cycles, the specimen was deemed a failure and the number of cycles at which the event occurred was recorded.

The data was statistically analyzed using Fisher's exact test. Statistical significance was set at 0.05. The log-rank test was performed for comparing Kaplan-Meier survival curves for the failed specimens.

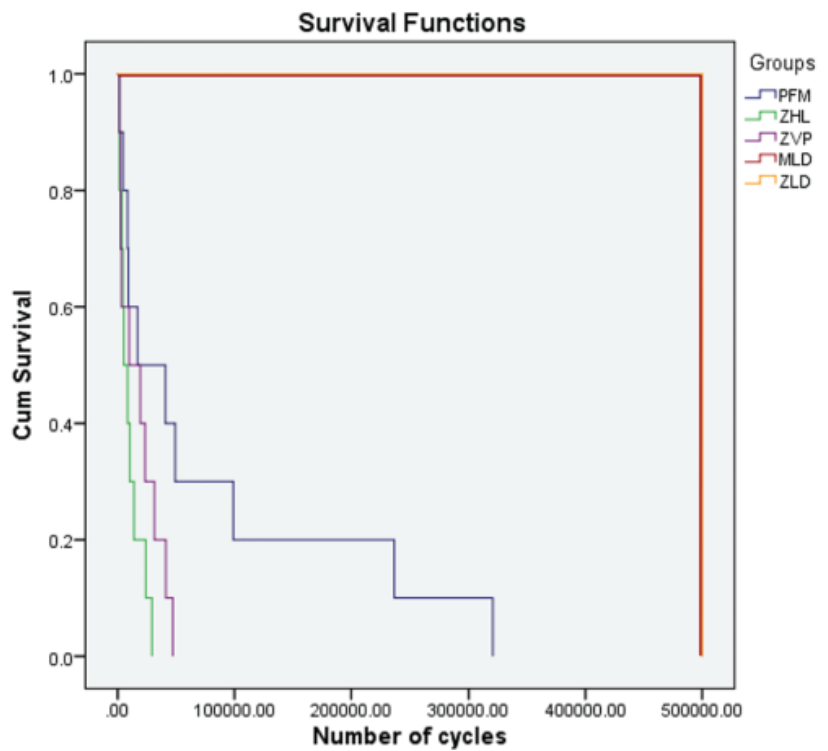

Fig. 2. Survival results for all groups. MLD and ZLD withstood the fatigue test with no failures, while ZHL, ZVP and PFM crowns underwent failure at different stages of the fatigue test

MLD - monolithic lithium-disilicate glass-ceramic crowns; ZLD - zirconia coping veneered with milled lithium-disilicate glass-ceramic; ZHL - zirconia copings veneered by hand-layering technique; ZVP - zirconia copings veneered by heat-pressing technique; PFM - porcelain-fused-to-metal crowns.

\section{Results}

Monolithic LDGC crowns (MLD) and crowns made with zirconia copings and veneered with LDGC veneers (ZLD) survived the entire fatigue test without any failures. In contrast, all specimens in the PFM, ZHL and ZVP groups underwent failure at different points of the cyclic loading test (Table 2). Fisher's exact test revealed a statistically significant difference among the groups $(\mathrm{p}<0.001)$. Therefore, the null hypothesis was rejected.

Bi-layered zirconia crowns veneered either by the handlayering technique or the press-on technique had the worst performance to chipping resistance. These were followed by the PFM crowns, which all failed before the fatigue testing was completed; however, after a number of cycles greater than those in the ZHL and ZVP groups. The Kaplan-Meier test revealed significantly higher survivability of the LDGC crowns (MLD) and zirconia crowns veneered with milled LDGC veneers as compared to the remaining 3 groups (Fig. 2).

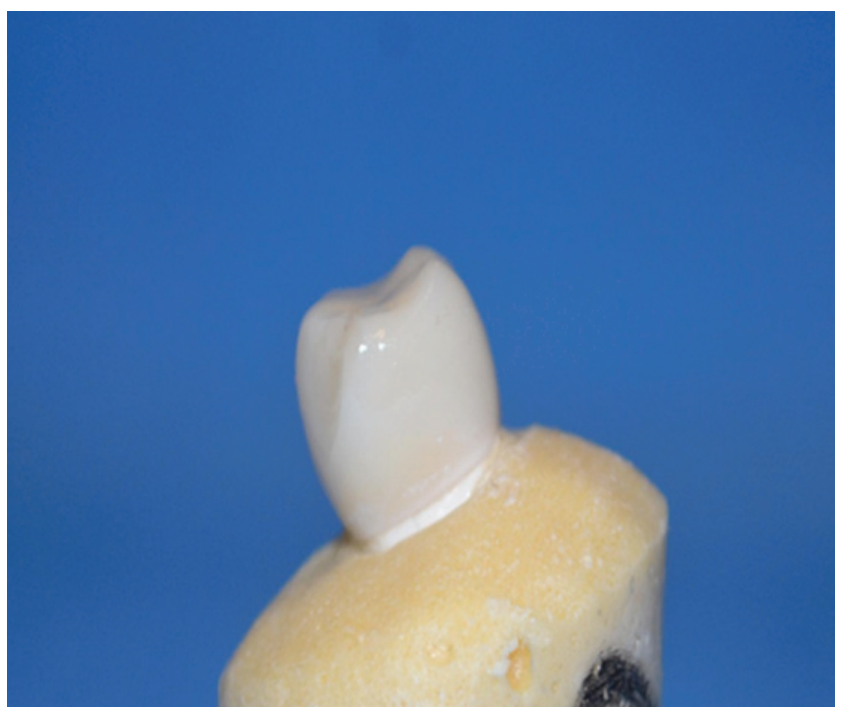

Fig. 3. Chipping of the veneering porcelain of a specimen in the ZVP (zirconia copings veneered by heat-pressing technique) group (cohesive failure) 

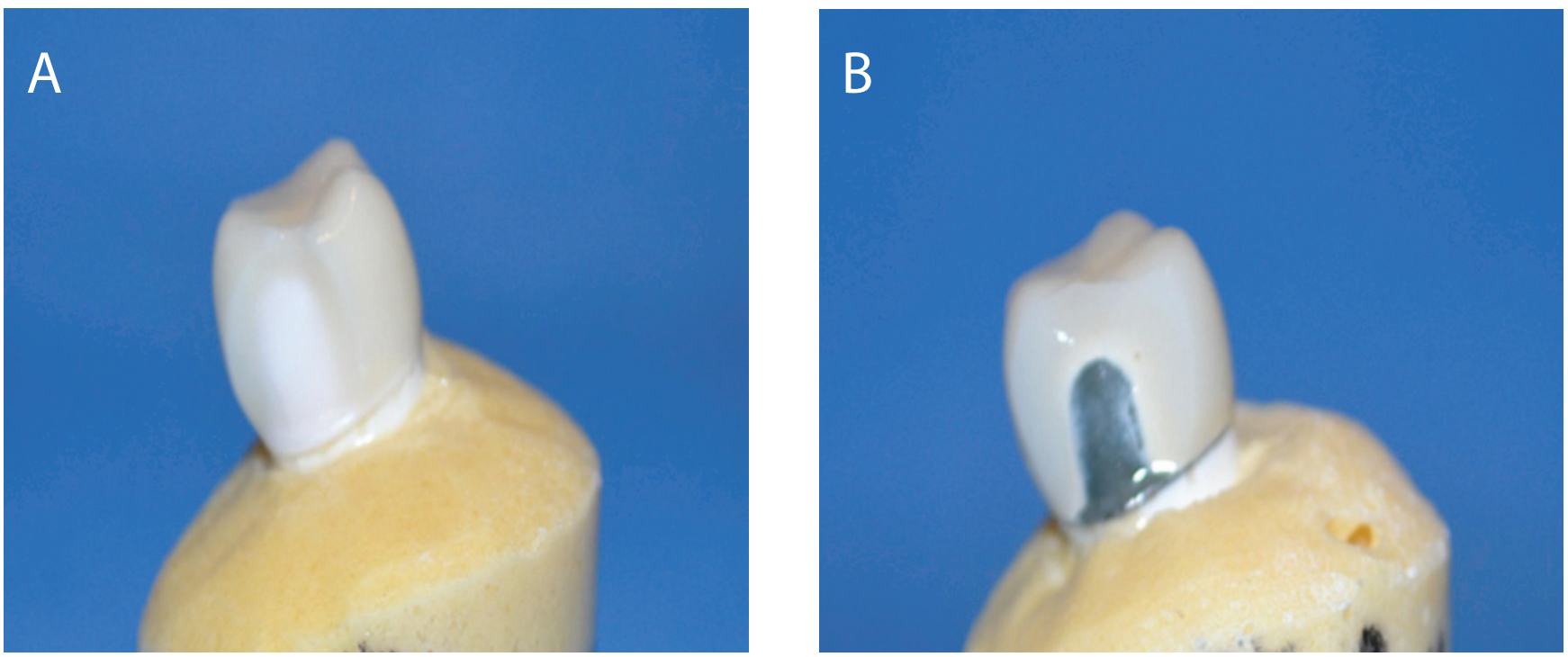

Fig. 4. Core/veneer interface delamination in a specimen in the ZHL (zirconia copings veneered by hand-layering technique) group (A) and PFM (porcelain-fused-to-metal crowns) group (B)

Bulk fracture was not observed with any of the specimens; however, cohesive failure within the veneering porcelain was frequently observed (Fig. 3). Core/veneer interface separation was observed in $2 \mathrm{ZHL}$ specimens and 4. PFM specimens (Fig. 4).

\section{Discussion}

Ceramic materials are prone to slow crack growth during cyclic loading in an aqueous environment. The combination of a moist environment and stresses during functioning increases the potential for crack propagation and reduces the load required for failure. ${ }^{23}$ The test used in the present study was performed while the specimens were maintained under water in order to counteract heat buildup at the point of contact due to friction, and to keep the test conditions clinically-relevant. The load cycle selected $(50-450 \mathrm{~N})$ is within the range of occlusal biting forces encountered in the posterior region. ${ }^{24}$ Considering that 2,700 chewing cycles per day are reported as the average for a young adult, this would add up to 1 million cycles per year. ${ }^{25}$ However, since not every chewing cycle is as active as the one selected in the present study, it was suggested that the total number of cycles should be divided by a factor ranging from 5 to $20 .^{26}$ Thus, 500,000 load cycles equate to 5-10 years of functioning. Based on this, it may be assumed that monolithic molar crowns made of LDGC and bi-layered molar crowns made of zirconia cores veneered with LDGC veneers would be expected to resist cuspal chipping from 5 to 10 years under the mechanical conditions of the oral environment. However, this finding must be interpreted with caution since posterior teeth are subjected to a variety of forces during functioning, and not only compressive ones. This includes shear forces that occur during lateral excursions of the mandible, which are an integral component of the chewing cycle. In addition, there are other factors in the oral environment that may influence the performance of ceramic restorations such as temperature and $\mathrm{pH}$ fluctuations, enzymatic challenges, and muscular volume. Combined, these factors may result in a shorter survival term to cuspal chipping; however, only further research can determine their exact effect.

The incidence of veneering porcelain chipping or delamination in a bi-layered zirconia crown has been reported as a major complication in the dental literature. ${ }^{19,27}$ Two reasons that could explain this incidence are core thickness and design. In the present study, the metal and zirconia coping were designed with even thickness. This results in an uneven porcelain veneer layer when anatomical features of the occlusal surface were recreated during the fabrication of the veneer. For a thick porcelain layer supported by zirconia coping with low thermal diffusivity, there is a higher risk of buildup of residual tensile stresses within the veneering porcelain layer. ${ }^{28}$ Such stresses may promote crack propagation, and hence increase the veneering porcelain susceptibility to undergo chipping.

Both types of bi-layered zirconia crowns veneered with hand-layered veneering porcelain and pressed porcelain veneer failed prematurely at a comparable mean number of load cycles. This may be due to inadvertent inclusion of voids within the veneering porcelain during fabrication; however, this would be less likely to happen in the case of heat-pressed veneer. It may also be due to the low bond strength between the zirconia and the veneering porcelain. ${ }^{11,29}$ Preis et al. observed outstanding fracture resistance of heat-pressed porcelain because of the improvement in the microstructure of the material. ${ }^{30}$ In agreement with the findings of the present study, Stawarczyk et al. found a slightly better or similar fracture resistance when comparing press-on and manually-layered veneering porcelain irrespective of the material used. ${ }^{7}$ 
The fact that 1 experienced technician applied the porcelain may have maintained the incidence of voids within the manually-layered veneering porcelain at the same level. However, the variability in CTE between the veneering porcelain and zirconia has a detrimental effect on the bond strength and strongly influences the resistance ability of the veneering porcelain to chipping. ${ }^{12}$ Ideally, the veneering porcelain should have a slightly lower CTE than that of the zirconia core in order to create slight compressive stresses within the veneering layer. These stresses might increase the bond strength between zirconia and the veneering porcelain. ${ }^{13}$ Accordingly, the CTE mismatch between the veneering porcelain and zirconia coping used in the present study (Table 1 ) resulted in the optimal bonding between the 2 structures; however, this was not enough for the crowns to adequately resist cuspal chipping under conditions of fatigue testing.

In the present study it was observed that porcelain-veneered zirconia crowns are more susceptible to chipping than PFM crowns, and both were less resistant to mechanical fatigue than zirconia crowns veneered with LDGC veneers. This result is in agreement with findings reported in several clinical studies that compared the longevity of zirconiabased and PFM crowns. ${ }^{8,27}$ The similarity of the mechanical properties and composition of the 2 veneering materials, IPS e.max Ceram and ZirPress, could explain their comparable chipping behavior. In contrast, the void-free and stronger veneering material (LDGC) resisted chipping in CAD-on crowns for the entire length of the mechanical fatigue test.

In the present study, cohesive failure occurred within the veneering layer in all crowns in the ZVP group. This indicates the presence of adequate bonding at the interface between zirconia coping and the porcelain veneer. Fischer et al. stated that porcelain chipping takes place within the porcelain layer rather than at the porcelain/ zirconia interface. ${ }^{31}$ Adhesive fracture is less often observed in zirconia bi-layered restorations, and in the present study it was observed with in 2 crowns in the ZHL group. ${ }^{7}$ On the other hand, PFM crowns showed higher chipping resistance compared to zirconia-based ones, and the fracture took place at the metal core/veneer interface in almost half of the specimens. However, PFM crowns resisted chipping a little better than the crowns belonging to the 2 bi-layered zirconia groups (ZHL and ZVP).

LDGC material with a flexural strength of $360 \mathrm{MPa}$ increased the chipping resistance of monolithic and bilayered crowns compared to bi-layered ceramic crowns in which the veneering porcelain had a much less flexural strength of only $100 \mathrm{MPa} .{ }^{2,18}$ In a recent study that compared the chipping behavior of manually-veneered zirconia crowns with CAD-on veneered ones under thermocycling and chewing simulation for 1.2 million cycles, $88 \%$ of the manually-veneered zirconia crowns failed during the chewing simulation, test while no failures were observed in the CAD-on crowns. ${ }^{18}$ Generally, this is in agreement with the findings of the present study.
In the present study, monolithic LDGC crowns showed higher cuspal chipping resistance compared to crowns belonging to the ZHL, ZVP and PFM groups. This is in agreement with findings reported by Guess et al., in spite of variations in the test design. ${ }^{21}$ The superior chipping resistance of monolithic LDGC crowns may be attributed to a number of factors. The e.max CAD blocks are manufactured under ideal manufacturing conditions, including operating in a vacuum, which results in minimizing the formation of voids or flaws. In addition, their microstructure includes fine grain lithium disilicate, which results in superior homogeneity. ${ }^{21}$ Furthermore, the monolithic configuration of LDGC crowns eliminated the interface between coping and veneer, which is the weak link in the bi-layered complex, where many failure modes are located. ${ }^{32}$ In a short-term clinical trial study, monolithic LDGC crowns (e.max CAD) showed successful outcomes with no technical complications such as occlusal chipping or fracture. ${ }^{20}$

Some of the limitations of the present study include lack of periodontal ligament simulation in the specimens. The specimens were rigidly attached to resin bases. This would not allow any mobility during the cyclic loading test. Having a simulated periodontal ligament in the specimen could have acted as a cushion and resulted in better stress distribution. In addition, the cyclic loading test was performed at a relatively high frequency $(20 \mathrm{~Hz})$ compared to what would be expected to occur in the oral environment, and indeed in comparison to the $1-2 \mathrm{~Hz}$ reported in other studies. However, Zahran et al. investigated the fatigue resistance of 2 all-ceramic crown systems where the compressive load cycles ranged from $50 \mathrm{~N}$ to $600 \mathrm{~N}$ at $20 \mathrm{~Hz}$, and their results were comparable to those reported in other studies, where a lower cycle frequency was followed. ${ }^{33}$ Therefore, perhaps the relatively higher cycle frequency followed in the present study had little or no effect on the outcome.

\section{Conclusions}

Within the limitations of the present in vitro study, crown chipping occurred with all specimens of the bi-layered crown groups: zirconia copings veneered with manually-added porcelain, zirconia copings veneered with heatpressed porcelain and PFM crowns. All monolithic LDGC crowns and zirconia crowns veneered with LDGC veneers survived the entire 500,000-cycle compressive fatigue test without any failures. Therefore, it is concluded that the latter 2 types of all-ceramic crowns would be expected to perform clinically better in terms of resistance to chipping and fracture under occlusal loads of mastication.

For bi-layered crowns, core material (zirconia vs metal) had an effect on the resistance of the crowns to cuspal chipping, with metal copings providing better resistance to cuspal chipping. 


\section{References}

1. Miyazaki T, Hotta Y, Kunii J, Kuriyama S, Tamaki Y. A review of dental CAD/CAM: Current status and future perspectives from 20 years of experience. Dent Mater J. 2009;28:44-56.

2. Beuer F, Schweiger J, Eichberger M, Kappert HF, Gernet W, Edelhoff D High-strength $\mathrm{CAD} / \mathrm{CAM}$-fabricated veneering material sintered to zirconia copings: A new fabrication mode for all-ceramic restorations. Dent Mater. 2009;25:121-128.

3. Piconi C, Maccauro G. Zirconia as a ceramic biomaterial. Biomater 1999;20:1-25

4. Guess PC, Schultheis S, Bonfante EA, Coelho PG, Ferencz JL, Silva NRFA. All-ceramic systems: Laboratory and clinical performance. Dent Clin North Am. 2011;55:333-352.

5. Manicone PF, Rossi lommetti P, Raffaelli L. An overview of zirconia ceramics: Basic properties and clinical applications. J Dent. 2007;35:819-826.

6. Benetti P, Pelogia F, Valandro LF, Bottino MA, Bona AD. The effect of porcelain thickness and surface liner application on the fracture behavior of a ceramic system. Dent Mater. 2011;27:948-953.

7. Stawarczyk B, Özcan M, Roos M, Trottmann A, Sailer I, Hämmerle CHF. Load-bearing capacity and failure types of anterior zirconia crowns veneered with overpressing and layering techniques. Dent Mater. 2011;27:1045-1053.

8. Heintze SD, Rousson V. Survival of zirconia- and metal-supported fixed dental prostheses: A systematic review. Int J Prosthodont. 2010;23:493-502

9. Özkurt Z, Kazazoĝlu E. Clinical success of zirconia in dental applications. J Prosthodont. 2010;19:64-68.

10. Schwarz S, Schröder C, Hassel A, Bömicke W, Rammelsberg P. Survival and chipping of zirconia-based and metal-ceramic implant-supported single crowns. Clin Implant Dent Relat Res. 2012;14(Suppl 1):e119-e125.

11. Christensen RP, Ploeger BJ. A clinical comparison of zirconia, metal and alumina fixed-prosthesis frameworks veneered with layered or pressed ceramic: A three-year report. J Am Dent Assoc. 2010;141:1317-1329.

12. Ishibe M, Raigrodski AJ, Flinn BD, Chung KH, Spiekerman C, Winter RR. Shear bond strengths of pressed and layered veneering ceramics to high-noble alloy and zirconia cores. J Prosthet Dent. 2011;106:29-37.

13. Rekow ED, Silva NRFA, Coelho PG, Zhang Y, Guess P, Thompson VP. Performance of dental ceramics: Challenges for improvements. J Dent Res. 2011;90:937-952.

14. Aboushelib MN, Feilzer AJ, De Jager N, Kleverlaan CJ. Prestresses in bilayered all-ceramic restorations. J Biomed Mater Res B Appl Biomater. 2008;87:139-145.

15. Tinschert J, Schulze KA, Natt G, Latzke P, Heussen N, Spiekermann H. Clinical behavior of zirconia-based fixed partial dentures made of DC-Zirkon: 3-year results. Int J Prosthodont. 2008;21:217-222.

16. Thompson JY, Stoner BR, Piascik JR, Smith R. Adhesion/cementation to zirconia and other non-silicate ceramics: Where are we now? Dent Mater. 2011;27:71-82.

17. Aboushelib MN, Feilzer AJ, Kleverlaan CJ. Bridging the gap between clinical failure and laboratory fracture strength tests using a fractographic approach. Dent Mater. 2009;25:383-391.

18. Schmitter M, Mueller D, Rues S. Chipping behaviour of all-ceramic crowns with zirconia framework and CAD/CAM manufactured veneer. J Dent. 2012;40:154-162.

19. Reich S, Fischer S, Sobotta B, Klapper HU, Gozdowski S. A preliminary study on the short-term efficacy of chairside computer-aided design/computer-assisted manufacturing generated posterior lithium disilicate crowns. Int J Prosthodont. 2010;23:214-216.

20. Fasbinder DJ, Dennison JB, Heys D, Neiva G. A clinical evaluation of chairside lithium disilicate CAD/CAM crowns: A two-year report. J Am Dent Assoc. 2010;141:10S-14S.

21. Guess PC, Zavanelli RA, Silva NR, Bonfante EA, Coelho PG, Thompson VP. Monolithic CAD/CAM lithium disilicate versus veneered Y-TZP crowns: Comparison of failure modes and reliability after fatigue. Int J Prosthodont. 2010;23:434-442.

22. Haddad MF, Rocha EP, Assunção WG. Cementation of prosthetic restorations: From conventional cementation to dental bonding concept. J Craniofac Surg. 2011;22:952-958.
23. Teixeira EC, Piascik JR, Stoner BR, Thompson JY. Dynamic fatigue and strength characterization of three ceramic materials. J Mater Sci Mater Med. 2007;18:1219-1224.

24. Helkimo E, Carlsson GE, Helkimo M. Bite force and state of dentition. Acta Odontol Scand. 1977;35:297-303.

25 . Kelly JR. Clinically relevant approach to failure testing of all-ceramic restorations. J Prosthet Dent. 1999;81:652-661.

26. Wiskott HW, Nicholls Jl, Belser UC. Stress fatigue: Basic principles and prosthodontic implications. Int J Prosthodont. 1995;8:105-116.

27. Rinke S, Schäfer S, Lange K, Gersdorff N, Roediger M. Practicebased clinical evaluation of metal-ceramic and zirconia molar crowns: 3-year results. J Oral Rehabil. 2013;40:228-237.

28. Swain MV. Unstable cracking (chipping) of veneering porcelain on all-ceramic dental crowns and fixed partial dentures. Acta Biomater. 2009;5:1668-1677.

29. Tsalouchou E, Cattell MJ, Knowles JC, Pittayachawan P, McDonald A. Fatigue and fracture properties of yttria partially stabilized zirconia crown systems. Dent Mater. 2008;24:308-318.

30. Preis V, Letsch C, Handel G, Behr M, Schneider-Feyrer S, Rosentritt M. Influence of substructure design, veneer application technique, and firing regime on the in vitro performance of molar zirconia crowns. Dent Mater. 2013;29:e113-e121.

31. Fischer J, Grohmann P, Stawarczyk B. Effect of zirconia surface treatments on the shear strength of zirconia/veneering ceramic composites. Dent Mater J. 2008;27:448-454.

32. Zhang Y, Lee JJW, Srikanth R, Lawn BR. Edge chipping and flexural resistance of monolithic ceramics. Dent Mater. 2013;29:1201-1208.

33. Zahran M, El-Mowafy O, Tam L, Watson PA, Finer Y. Fracture strength and fatigue resistance of all-ceramic molar crowns manufactured with CAD/CAM technology. J Prosthodont. 2008;17:370-377. 
